\title{
Challenges on Electric Charging Stations with Solar Power Generator Integration
}

\author{
S.V. Phanidhar ${ }^{1}$, K. Lokeswararao ${ }^{2}$ B Venkateshnaik ${ }^{3}$ \\ ${ }^{1}$ GITAM, India, psudani@ gitam.edu \\ ${ }^{2}$ GITAM, India, lokeshch85@ gitam.edu \\ ${ }^{3}$ GITAM, India, vbanakar@ gitam.edu
}

\begin{abstract}
The plug in electric vehicle substantiates its presence in the market the installation of the charging stations and the dynamic controls needed for a steady state working of them are scrutinized and developed. The lesser number of chargers for many plug in vehicles, voltage maintenance for the distribution feeders, better bidirectional operation of the power in PV source, MPPT based control for battery storage. A composite controller for the Battery Energy Management system (BEMS) with the bidirectional controller with nominal power delivery to the PEVS can be developed. A composite controller that would comprise of all these indications in a single composite controller would be a scope that is to be developed for further work. A grid connected system which makes sure that there is a $24 \mathrm{hr}$ supply of the charging available with the PV based charging stations connected to the distribution system.
\end{abstract}

Key words: Electric Vehicle, Renewable Energy, Charging Stations.

\section{INTRODUCTION}

one of few earliest publications based on the electric vehicles dates back to January 1897 which discusses the pros and cons of using the electric vehicle in the rail track transportation [1]. The transaction discusses about the disadvantages of the battery size that is found to be heavy during that time. The discussion puts stress on the fact that the electric vehicle would be possible only if the size of the batteries is reduced and also the power that can delivered from the battery must have a higher power to weight ratio. It is evident that battery technology during those days was not fully grown to the extent it is today. It is concluded that one day the electrical facility will be so well distributed that there would be facility of charging the vehicles all over the places. In [2] the engineers both from the steam engine and the electric engine fraternity met to discuss the choice of motor and its characteristics in the traction system. The literature is seen to be scrutinizing the gear ratio and on how the motorman (locomotive operator) would drift the vehicles at different road conditions were analyzed in the literature since it affects the motor characteristics.

Although the discussion about the improvement of the electrical vehicle started during early 1900's with discussion on battery and vehicle manufacturing, regenerative braking in electric vehicles, space vehicles using solar for driving itself [3-14] the foundation for the recent trend in the electric vehicle research is laid during the 1970's since the introduction of many power electronic devices and the improvement in the battery technology [15-21]. This Paper focuses on the portability of the electric vehicle supply. Although a solar powered vehicle is possible the amount of solar power gathered from the solar panel that comprises the body of the vehicle would be useful for supplying the automotive electronics process in the vehicle. Keeping this in mind the portability is constrained to having an electric vehicle charging station which is time and distance feasible. The improvement in the solar power usage compatibility has brought in new hopes on developing solar based charging stations. This Paper reviews the literature which focuses on the recent advances in the solar based electric vehicle charging stations for electric vehicles having modern energy management techniques with both standalone and the grid connected Solar Energy System.

Advent of different power electronics control technique and power processing units is paving way to highly efficient and environment solutions for the electric vehicle powering devices. The Photovoltaic (PV) power becoming a popular adaptation in developing countries are bringing about an evident change in the usage of electric vehicles for transit.

\section{PV BASED ELECTRIC CHARGING REVIEW}

In [22] a model is developed with the perspective of an investor to install a PEV charging stations in the city considering the random behavior of the customers and their demands. The cost minimization due to both facilities supporting practical operation and for practical operation acts as the objective of the model. A multiple-charger multiple-port charging (MCMP) is used in the model to use limited number of the chargers to charge more PEVS. A coordinated method of charging in a parking lot is developed on the MCMP units using the stochastic programming model. Different connection models for the chargers with the parking spaces are tested and a consolidation of analysis of different planning model is generalized.

A MPPT controlled PV model is developed for 10 e-rickshaws which connects intermittently at different time intervals to the PV bus [23]. A strategy that mitigates the effects of intermittent connection of the EVs on the PV bus is developed. A hybrid planning method (HPM) on the distribution system suiting for a multiyear investigation on the cost benefits is projected to the smart charging approach on the PEV. An integrated approach which combines both grid-to-vehicle and the vehicle-to-grid 
charging framework is utilized to control the smart charging control technique in [24]. The total daily cost which is the economic perspective and peak to average ratio minimization which is the technical perspective in improving the performance of charging the electric vehicles. There are two approaches of planning for charging the electrical vehicles with both the day and night version. A multiyear cost benefit analysis is carried for both the charging strategies with conventional charging method (CPM) and the Hybrid Charging Method (HPM) on a small scale distribution network is realized and observations are tabulated. The study is validated by applying the simulation on the distribution using both the CPM and the HPM and it is found that the proposed HPM to be highly effective, feasible and scalable.

The publication [25] on residential PV system based PEV charging is discussed with solutions to voltage quality problems in low voltage distribution networks (LVDNs). The variation of the voltage between two buses would introduce the reactive power injection. Thus a strategy that combines the battery energy management and the PV active power curtailment is utilized to improve the voltage imbalance thus improving the overall voltage quality problems. The storage capacity of the PEV batteries which is limited and the State of Charge (SOC) of the batteries are effectively exploited in distribution control strategy proposed in [25] which acts as one of the two consensus algorithm developed. Another consensus is to share the curtailment of the real power from the PVs while there is an overvoltage condition occurring. Both the overloading condition that occurs due to the reverse flow of power and the sag in voltage due to higher load is compensated in the method discussed in the literature. As a whole the algorithm is to coordinate the charging and discharging of the PEVs batteries thus making sure that the power utilization is highly effective in the distribution network. And also the active power that is curtailed from the PV source is minimized due to the charging coordination. A three phase four wire LVDN system is used for this study with PV source.

Although there is a stochastic nature in the Renewable Energy Sources (RES) the control techniques that best utilizes the available power from the RES is a possibility with the Energy Storage Systems (ESS). This ESS is riding a new role while the EV charging and discharging is adopted. In [26] an expansion planning with multistage distribution system is modeled for evaluating the investments that include RES, ESS and EV charging station installation. The travel pattern of the EVs is considered along with the modeling of the RES variability scenarios and a uncertain demand scenarios for developing the ESS. The scenario of uncertainties are generated using the k-means++ clustering algorithm which maintains a safe correlation among the uncertain sources. A mixed integer linear program based optimization algorithm is developed to minimize the cost which includes losses, investment, non-supplied energy maintenance and production. A 54 node test system is used for this purpose.

An optimization algorithm that would schedule the energy exchange from the grid considering the grid constraint with the work space charging system powered from the PV energy source is introduced in [27]. The chances of vehicle to grid power supply due the vehicle's long stay at the parking lot is analyzed in the single EV charger charging multiple EVs with regulation and controlling overloading conditions in the grid. A EV's fleet is charged from the PV by controlling the multiple EV charging using a single charger and the grid regulation with overloading control using the mixed integer linear programming (MILP) in [27]. The comparison with the immediate and average rate charging policies this MILP based system has shown a $32 \%$ to $651 \%$ reduction in the net cost of EV charging from PV.

A commercial building based PV supplied EV charging station with the fixed battery storage system with the bidirectional power flow control is developed with four-stage intelligent optimization and control algorithm [28]. The involved four stages include day ahead schedules for energy management, price updation multitier based and bonus for discharging participation, hour ahead schedule of energy management optimization and control in real time. Though there are unpredictable conditions occurring in the PV supply or overload, the algorithm contributes in providing the incentives to the participants who spare their EVs for discharging while needed and the overall cost is reduced while a reliable power delivery is maintained in the building. The case studies carried out with the proposed algorithm indicates that the operational cost is reduced and also there is a higher tolerance while uncertainty occurs.

A charging scenario which capitalizes trading of vehicle to grid (V2G) energy, while sensing the topological variation in the distribution network (DN) with multiple Microgrids (MGs) connected to the network [29]. The properties chosen for optimizing the incentives for charging/discharging are 1) rationality of the individual, 2) social cost minimization and the 3) truthfulness. The MG and the DN has two separate V2G auctions which optimizes the charging /discharging control of the EVs by the minimization algorithm applied on the social cost with the network topology constraints. And in the similar way a auctioning framework between both the MG and DN is developed that enable the power exchange between them is coordinated. All the three economic properties would hold for both the grid tied and the islanded mode of the MGs. And even the voltage regulation is observed within a secured range in the proposed work.

A total system energy cost minimization algorithm for optimizing the multiple EV charging stations connected to the distribution network with both the power and voltage constraints in the bus is satisfied [30]. Predictive models that operate in short term with the help of the information that is got recently is considered for optimization. A convex relaxation method would convexify the problem by means of the bus injection model to obtain the optimal solution globally with efficient output. While optimizing the concerns like the EV uncertainties, data privacy and the economic interests of the individuals are considered. A Fuzzy rule based dispatching of the optimal charging discharging schedules is carried out by considering the departure of each vehicle. An IEEE 15 bus distribution system is used to demonstrate the validity of the algorithm.

A method that coordinates the power and voltage profiles between the home energy management system (HEMS) and grid energy management system (GEMS) in order to supply both the residential load and the EV charging/discharging setup while maintaining the reduced operation cost in residential and also attaining PV curtailment without disturbing the EV usage. The control of the HEMS works on the plan that is already determined and the data gathered from the real time monitoring. The simulation carried out on the distribution system from Japan works with objective function that is meant to reduce the PV curtailment and the residential cost of operation [31]. 
A $10 \mathrm{KW}$ EV charger is developed using the supplies comprising of both PV based and three phase grid based. This combined charging implementation applies the Chademo protocol that would maintain a continuous power delivery to the EVs with the higher power density and efficient converter with three ports used commonly for EV, PV and the grid power. Four different power delivery scheme $\mathrm{PV} \rightarrow \mathrm{EV}, \mathrm{EV} \rightarrow$ grid, grid $\rightarrow$ $\mathrm{EV}$, and $\mathrm{PV} \rightarrow$ grid are controlled in the implementation. This topology which comprise the DC link in between the PV to EV is said to be successful in delivering a high power density with higher switching frequency since the use of silicon carbide devices are used. Compared to the existing solutions the topology defined in the literature delivers around three times the power density with higher peak and the partial load efficiency [32].

The active power and reactive power control of the grid and the coordinated EV charging on a 33 node distribution network in order to maintain unity power factor in the grid is developed. The model consisting of both the power flow to the grid and the EV charging with reactive power supply to the grid with more than $5000 \mathrm{EVs}$ connected to the network [33]. The results from the analysis indicate that there can more number of EVs that can be incorporated while maintaining the unity power factor. A decentralized coordination of EV charging using the fuzzy based controller is developed that is capable of charging the EVs at any point in the distribution network with different voltage levels also. The cost meant for communication of the factors like the time to charge and the energy needed for charging along with the voltage at the point where the EVs are connected [34].

Unscheduled increase in the number of electric vehicles included for charging would increase the peak load on the distribution network thus increasing the power quality issues on the grid. An AC charging to modify the PEV charging is developed [35].

The concept of reducing the expansion of the grid expansion power is adopted by implementing the stationary storage unit which buffers the energy from the grid to the electric vehicles and buffers back to the electric vehicles when needed[36] . It is observed that the total need of the grid power reduces from $1800 \mathrm{~kW}$ to $500 \mathrm{~kW}$ is a stationary battery power of $1000 \mathrm{kWh}$ capacity is installed.

The literature discusses about the high power conductive on board chargers which is capable of both the unidirectional and bidirectional power flow in the EVs. The global trend in the different charging standards are discussed including the EV's wireless charging technology and the auxiliary power module are discussed in detail[37].The different converter topologies involved in the OBC implementation is observed.

A survey of different charging load modeling of the EVs is carried out and future prospects for the same are obtained in the literature. The modeling of the EV charging for better efficiency and safety standards are discussed in detail. A research approach which reduces the inherent problems in the EV charging load scaling is introduced [38].

With multiple options for different charging types like the type-1, type-2 and DC fast charging the scheduling patterns must have a sophisticated infrastructure to deal with the dynamism involved in the EV charging. Two types of scheduling algorithms both static and dynamic charging paradigm is introduced in the optimization algorithm that would find the optimal scheduling using both the static and the dynamic scheduling frame work. Mixed integer optimization algorithm with multi-objective is dealt[39].

The three phase power based battery charging and discharging strategy that reduces the cost of charging/discharging and degradation cost of battery while used for discharging. And another strategy which maintains a higher local peak load shifting while reducing the discharging cost due to V2G activity. A 75 node test feeder is used for the testing of both the scenario along with the other criteria like the sudden addition of the vehicle in the charging pool and different travel scenarios [40].

A Fuzzy logic based inference engine is developed to automate the charging and discharging of the EVs connected to the grid. The idea about the peak EV charging load is made available since the power must be within the power limit of the grid. The uncertain parameters that are obtained from the EVs and the parking capacity is used to develop the accurate charging and discharging paradigm in the parking facility [41].

The Autonomous electric vehicles (AEVs) travel plan based dynamic distribution network reconfiguration (DDNR) is developed in the literature. A 33 node test feeder is provided for the implementation and it is observed that the reconfiguration is able to satisfy the AEV charging and discharging according to the travel plan. The implementation used the mixed integer programming for the implementation [42].

The literature combines the solar input with the grid power to supply the EV charging strategy. A finite time approach is developed in which an arbitrary usage of EVs is gathered to get the energy management strategy for load scheduling in real time. An optimization algorithm to obtain low scheduling delays, and cost for EV power procurement is carried out. Obtaining better PV power sufficiency and battery degradation employing the Lyapunov optimization technique is evident. Applied with different whether conditions the method has reduced the bill up to $72.61 \%$ among other advantages [43].

A game theory approach to schedule the EV charging is obtained for consumption preference that varies. A smart community (SC) based scheduling using game theory approach is applied with three parties. EVs, grid and aggregators are three parties in the game theory approach. The reliability of the aggregators is considered as the trust model to improve the power trading safety. With the said condition the stackelberg game with four stage is developed around the scheduling problem. The available limited renewable energy is fairly shared with better efficiency among the EVs [44].

An optimal control and configuration of the EV Aggregation(EVA) for reduced operating cost of the being the main problem and a sub-problem which plans the charging of the EVs is obtained on the distribution network supplying the EVA with smart meters connected to it. A a mixed integer nonlinear programming (MINLP) with Benders decomposition technique is adopted for the implementation. A 123 bus network is adopted for proving the algorithm developed [45]. A classification algorithm using Support Vector Machine as a classifier is utilized to develop the protection scheme for anti-islanding in the system which comprise of PV supplying the plug in vehicles also connected to grid. The DC side short circuit during the fast charging phase would introduce a power transient at the grid side thus reckoning this classification method by sensing seven important variables sensed at the PCC. The classification efficiency and other important metrics are found to be satisfactory [46]. 
A control technique that would manage between the EVs that participate in day ahead scheduling and that don't participate by using the two class tariff for charging while distributed network impact is managed. The objective of the control technique is to manage the win-win situation between the distribution network and the consumer [47].

A comparative analysis of the $\mathrm{Co} 2$ emission from the EV and the internal combustion engine is carried out by creating the Indian condition from the city Aligarh India with different charging means. The performance validation of the EV with the integrated solar charger on it is carried out[48].

The use of many EVs has led to need of many charging stations in the place of use. The placement of the chargers are important since the EVs will be spread widely. A data driven placement of the EV chargers is carried out in the literature which reduce the movement of the driver to move a long distance to attain the station. Genetic Algorithm based placement of the charging station in the city of Boston, USA is carried out[49].

Fast charging station allocation in the United States is developed where the constraints like the practicality, interest of the people involved and few underlying constraints are used. The node serving approach is considered to be an important method that is applied on the grid to vehicle implementation [50].

An integrated charging device that for the EVs is compatible with almost every type of the supply available in the usage by means of connecting it directly to many types of supplies including the renewable supply, DC micro girds and the storages. The bidirectional power flow like G2V, V2Vand V2G is possible along with simultaneous driving and charging is possible [51].

The distribution company uses the Vehicle for Grid (VfG) technology that is only to maintain better distribution system by using the V2G and G2V technologies. The VfG is solely used for the distribution grid power maintenance by providing the services of $\mathrm{V} 2 \mathrm{G}$ and $\mathrm{G} 2 \mathrm{~V}$ by applying it in optimal time period [52], [56], [57].

\section{CONCLUSION}

A detailed survey of literature on recent trends on the Electric Vehicle charging with solar energy as the subsidiary source is discussed. Few problems identified while carrying on the literature survey include

1. The vehicle is used for grid operation must be optimally used for it is moving from one port to the other in the grid.

2. Options to reduce the number of sensing data need to be analyzed.

With the stipulated number of publications utilized it is made sure that every aspect of the EV charging like multiport charging station, V2G and G2V topologies, Smart meters, solar grid integrated charging, energy management system and few distribution network topologies are discussed.

\section{ACKNOWLEDGMENT}

No funding agency has funded us to carry out this paper work.

\section{REFERENCES}

1. Bates, Putnam A. et al. Electrically Driven Vehicles, Transactions of The American Institute of Electrical Engineers. A Topical Discussion at the 112th Meeting on the
American Institute of Electrical Engineers, New York, January 20th, 1897. President Duncan in the Chair.

2. RogerT.Smith ; W.A.Stevens ; A.H.Seabrook ; HEDLEY Thomson; H.E "The supply and transmission of power in self-contained road vehicles and locomotives, Journal of the Institution of Electrical Engineers, Volume: 49,Issue: 214,pp $118-143,1912$.

3. J.C. Macfarlane; H. Burge. The supply and transmission of power in self-contained road vehicles and locomotives, Journal of the Institution of Electrical Engineers, Volume:49, Issue:214, Page(s):93,1912.

4. J.B.G.Damoiseau Petrol-electric motor-vehicles, Journal of the Institution of Electrical Engineers, Volume: 51, Issue: 222,1913 , Page(s): $582-610$.

5. R.A. Chattock; S.T. Allen ; W. Fennell ; R.J. Mitchell; A.C. Soutter ; S.H.Bill. Discussion on Electric battery vehicles Journal of the Institution of Electrical Engineers Volume: 52 , Issue: 232 ,Page(s): 507 - 510, April 151914.

6. R.E.Hellmund. Regenerative Braking of Electric Vehicles, Transactions of the American Institute of Electrical Engineers (Volume: XXXVI ), Jan-1917, Page(s): 1-78.

7. H.E. Dance. The electric battery vehicle, Journal of the Institution of Electrical Engineers, Volume: 61,Issue: 323, October 1923.

8. L. Miller. The design of storage-battery locomotives for use in coal mines Journal of the Institution of Electrical Engineers, Volume: 64 , Issue: 358 , Page(s): 1004 - 1010, October 1926.

9. Ernst Weber et al. The electro gear-A new electromechanical vehicle drive, Electrical Engineering, Volume: 60,Issue:12,Page(s): 1308 - 1310, Dec. 1941.

10. W. A. Brecht, Charles Kerr, Electric Locomotives With Identical Basic Components Transactions of the American Institute of Electrical Engineers, Volume: 67, Issue: 1, Page(s):339 - 344, Jan. 1948.

11. H.W. Heyman The economic basis of battery electric road vehicle operation and manufacture Proceedings of the IEE - Part II: Power Engineering, Volume: 99, Issue: 71, Page(s): 465 - 472, October 1952.

12. Discussion on The recognition of moving vehicles by electronic means, before the Institution, 6th November, and the Mersey and North Wales Centre, at Chester, 24th November, 1958, Proceedings of the IEE - Part B: Radio and Electronic Engineering, Volume: 106, Issue: 26, Page(s): 195 19, March 1959.

13. C.D. Fredrickson. The effectiveness of photovoltaic solar cells as an electrical power source for space vehicles 1962, International Electron Devices Meeting, 09 August 2005.

14. B.S.Hender.Future of the battery-electric car, Electronics and Power, Volume: 10 , Issue: 8 ,Page(s): 250 254, August 1964.

15. J.V. Byrne; J.G. Lacy. Compatible controller-motor system for battery-electric vehicle, Proceedings of the Institution of Electrical Engineers, Volume:117,Issue:2,pp: 369 - 376, February 1970.

16. R.C. La France; R.W. Schult, An evaluation of electrical systems for hybrid vehicles, IEEE Vehicular Technology Conference, 19 June 2006

17. F. French ; G. Bradshaw ; L. Cohen ; V. Welch, A thyristor (SCR) phased controlled propulsion system with linear, regenerative characteristics for electricall powered vehicles, IEEE Vehicular Technology, IEEE Xplore: 19 June 2006. 
18. Y. Sahinkaya ; R. Sridhar, Minimum-energy control of a class of electrically driven vehicles,IEEE Transactions on Automatic Control, Volume: 17 , Issue: 1 , Page(s): 1 - 6, Feb 1972.

19. G.J. Murphy, Considerations in the design of drive systems for on-the-road electric vehicles, Proceedings of the IEEE, Volume: 60 , Issue: 12 , Page(s): 1519 - 1533, Dec. 1972.

20. John J. Morrison, Electronic control of battery electric vehicles, Radio and Electronic Engineer, Volume: 42 , Issue: 2 , Page(s): 91,February 1972.

21. R.C. LaFrance ; R.W. Schult, Electrical systems for hybrid vehicles, IEEE Transactions on Vehicular Technology, Volume: 22 , Issue: 1, Page(s): 13 - 19, Feb 1973.

22. Huimiao Chen ; Zechun Hu ; Haocheng Luo ; Junjie Qin ; Ram Rajagopal ; Hongcai Zhang, Design and Planning of a Multiple-Charger Multiple-Port Charging System for PEV Charging Station, IEEE Transactions on Smart Grid, Volume: 10 , Issue: 1 , Jan. 2019.

23. Sushant Kumar; Ritesh Kumar Keshri; H.M. Suryawanshi. Impact and Mitigation of Electric Vehicle Plug-in on the PV fed DC-bus Charging Station, IEEE Industrial Electronics Society, 21-23 Oct. 2018

24. Rahul Mehta, Dipti Srinivasan, Anupam Trivedi, Jing Yang. Hybrid Planning Method Based on Cost-Benefit Analysis for Smart Charging of Plug-In Electric Vehicles in Distribution Systems, IEEE Transactions on Smart Grid, Volume: 10, Issue: 1, pp: 523 - 534, Jan. 2019.

25. Mehdi Zeraati, Mohamad Esmail Hamedani Golshan, Josep M. Guerrero. A Consensus-Based Cooperative Control of PEV Battery and PV Active Power Curtailment for Voltage Regulation in Distribution Networks, IEEE Transactions on Smart Grid, Volume: 10, Issue: 1, Jan. 2019. 26. Pilar Meneses de Quevedo, Gregorio Muñoz-Delgado, Javier Contreras. Impact of Electric Vehicles on the Expansion Planning of Distribution Systems Considering Renewable Energy, Storage, and Charging Stations, IEEE Transactions on Smart Grid, Volume: 10 , Issue: 1, Jan. 2019. 27. Gautham Ram Chandra Mouli, Mahdi Kefayati, Ross Baldick, Pavol Bauer. Integrated PV Charging of EV Fleet Based on Energy Prices, V2G, and Offer of Reserves, IEEE Transactions on Smart Grid, Volume: 10 , Issue: 2 , March 2019.

28. Qin Yan, Bei Zhang, Mladen Kezunovic. Optimized Operational Cost Reduction for an EV Charging Station Integrated With Battery Energy Storage and PV Generation, IEEE Transactions on Smart Grid, Volume: 10 , Issue: 2 , March 2019.

29. Weifeng Zhong, Kan Xie, Yi Liu, Chao Yang, Shengli Xie. Topology-Aware Vehicle-to-Grid Energy Trading for Active Distribution Systems, IEEE Transactions on Smart Grid, Volume: 10 , Issue: 2 , March 2019.

30. Yu Zheng, Yue Song, David J. Hill, Ke Meng, Online Distributed MPC-Based Optimal Scheduling for EV Charging Stations in Distribution Systems, IEEE Transactions on Industrial Informatics, Volume: 15, Issue: 2, Feb. 2019.

31. Hiroshi Kikusato, Kohei Mori, Shinya Yoshizawa et al, Electric Vehicle Charge-Discharge Management for Utilization of Photovoltaic by Coordination Between Home and Grid Energy Management Systems, IEEE Transactions on Smart Grid, Volume: 10, Issue: 3 , May 2019.
32. Gautham Ram Chandra Mouli et al, A 10 kW Solar-Powered Bidirectional EV Charger Compatible With Chademo and COMBO, IEEE Transactions on Power Electronics, Volume: 34 , Issue: 2 , Feb. 2019 )

33. Zohaib Akhtar, Martin Opatovsky, Balarko Chaudhuri, Shu Yuen Ron Hui. Comparison of point-of-load versus mid-feeder compensation in $\mathrm{LV}$ distribution networks with high penetration of solar photovoltaic generation and electric vehicle charging stations, IET Smart Grid, Volume:2, Issue: 2, Page(s): 283 - 292, June 2019.

34. Jingyuan Wang, et al, Coordinated Electric Vehicle Charging With Reactive Power Support to Distribution Grids, IEEE Transactions on Industrial Informatics, Volume: 15 , Issue: 1 , Jan. 2019.

35. Samy Faddel, Osama A. Mohammed, Automated Distributed Electric Vehicle Controller for Residential Demand Side Management, IEEE Transactions on Industry Applications, Volume: 55, Issue: 1, Jan.-Feb. 2019.

36. Jingyuan Wang, Guna R. Bharati, Sumit Paudyal, Oğuzhan Ceylan, Bishnu P. Bhattarai, Coordinated Electric Vehicle Charging With Reactive Power Support to Distribution Grids, IEEE Transactions on Industrial Informatics, Volume: 15, Issue: 1, Jan. 2019.

37. Samy Faddel, Osama A. Mohammed, Automated Distributed Electric Vehicle Controller for Residential Demand Side Management, IEEE Transactions on Industry Applications, Volume: 55 , Issue: 1, Jan.-Feb. 2019.

38. Arian Zahedmanesh et al. Direct Control of Plug-In Electric Vehicle Charging Load Using an In-House Developed Intermediate Control Unit, IEEE Transactions on Industry Applications, Volume: 55 , Issue: 3 , May-June 2019. 39. Thomas S. Bryden, George Hilton, Borislav Dimitrov, Carlos Ponce de León, Andrew Cruden. Rating a Stationary Energy Storage System within a Fast Electric Vehicle Charging Station Considering User Waiting Times, IEEE Transactions on Transportation Electrification (Early Access ) 40. Alireza Khaligh, Michael D'Antonio. Global Trends in High-Power On-Board Chargers for Electric Vehicles, IEEE Transactions on Vehicular Technology, Volume: 68 , Issue: 4 , April 2019.

41. Yue Xiang, Shuai Hu, Youbo Liu, Xin Zhang, Junyong Liu. Electric vehicles in smart grid: a survey on charging load modelling, IET Smart Grid, Volume: 2, Issue: 1 ,3 2019. 42. Ramin Moghaddass, Osama A. Mohammed, Erotokritos Skordilis, Shihab Asfour. Smart Control of Fleets of Electric Vehicles in Smart and Connected Communities, IEEE Transactions on Smart Grid ( Early Access )Page(s): 1 - 1, April 2019

43. Yulong Huang. A Day-Ahead Optimal Control of PEV Battery Storage Devices Taking into Account the Voltage Regulation of the Residential Power Grid, IEEE Transactions on Power Systems ( Early Access )Page(s): 1 - 1, May 2019

44. Shahid Hussain, Mohamed A. Ahmed, Young-Chon Kim, Efficient Power Management Algorithm Based on Fuzzy Logic Inference for Electric Vehicles Parking Lot, IEEE Access, Volume: 7,Page(s): 65467 - 65485, May 2019 .

45. Zhaomiao Guo, Zhi Zhou, Yan Zhou, Impacts of Integrating Topology Reconfiguration and Vehicle-to-Grid Technologies on Distribution System Operation, IEEE Transactions on Sustainable Energy ( Early Access ),Page(s): 1 - 1,May 2019. 
46. Ashfaq Ahmad, Jamil Khan, Real-time Load Scheduling and Storage Management for Solar Powered Network Connected EVs, IEEE Transactions on Sustainable Energy ( Early Access ),Page(s): 1 - 1,June 2019.

47. A Novel Charging Scheme for Electric Vehicles with Smart Communities in Vehicular Networks, IEEE Transactions on Vehicular Technology ( Early Access )Page(s): 1 - 1,Date of Publication: 19 June 2019

48. Shuang Gao, Hongjie Jia, Integrated Configuration and Optimization of Electric Vehicle Aggregators for Charging Facilities in Power Networks with Renewables, IEEE Access ( Early Access ),Page(s): 1 - 1, June 2019.

49. Hamid Reza Baghaee, Dragan Mlakić, Srete Nikolovski, Tomislav Dragičević, Anti-Islanding Protection of PV-based Microgrids Consisting of PHEVs using SVMs, IEEE Transactions on Smart Grid ( Early Access ),Page(s): 1 - 1, June 2019

50. Sachin G. Argade, Visvakumar Aravinthan, Ismet Esra Büyüktahtakın, Siny Joseph, Performance and consumer satisfaction-based bi-level tariff scheme for EV charging as a VPP, IET Generation, Transmission \& Distribution, Volume: 13, Issue: 11, Page(s): 2112 - 2122, 2019.

51. Prashant Shrivastava, Mohammad Saad Alam, Mohammad Syed Jamil Asghar, Design and techno-economic analysis of plug-in electric vehicle-integrated solar PV charging system for India, IET Smart Grid, Volume: 2 , Issue: 2, Page(s): 224 - 232, 2019.

52. Vazifeh, Mohammad M. \& Zhang, Hongmou \& Santi, Paolo \& Ratti, Carlo, Optimizing the deployment of electric vehicle charging stations using pervasive mobility data, Transportation Research Part A: Policy and Practice, Elsevier, vol. 121(C), pages 75-91, 2019.

53. Yutaka Motoaki Location-Allocation of Electric Vehicle Fast Charger, Research and Practice World Electr. Veh. J. 2019, 10(1), 12.

54. Caniggia Viana et al, A Drivetrain Integrated DC Fast Charger with Buck and Boost Functionality and Simultaneous Drive/Charge Capability, IEEE Transactions on Transportation Electrification ( Early Access ),Page(s): 1 1, June 2019.

55. Mehdi Rahmani-Andebili, Vehicle-for-grid (VfG): a mobile energy storage in smart grid, IET Generation, Transmission \& Distribution, Volume: 13 , Issue: 8 , Page(s): 1358 - 1368, May 2019.

56. Mojtaba Khalilian1, Paolo Guglielmi, A Dual-Topology Wireless Power Transfer System with Constant Current or Constant Voltage Output for Battery Charging Application, International Journal of Engineering Research and Technology, ISSN 0974-3154, Volume 12, Number 2, pp. 237-244, Feb. 2020.

57. Dauda Duncan, Mmoloki Mangwala, Bokani Mtengi, Adamu Murtala Zungeru, Bakary Diarra, Joseph Chuma. Hybridization of Photovoltaic and Thermoelectric Energy Harvesting Systems at Seismic Nodes, International Journal of Engineering Research and Technology, ISSN 0974-3154, Volume 13, Number 9, pp. 2417-2428, September 2020.

58. K Lokeswara Rao, Phanidhar S V. Reliability Indices of a combined PV, Wind and Grid System, International Journal of Emerging Trends in Engineering Research, Volume 8. No. 9, pp No. 5238 - 5241, September 2020.

59. K Lokeswara Rao, SLV Sravan Kumar. Power Quality Enhancement of Grid Integrated Distribution System with Renewable Energy Sources ISSN International Journal of
Emerging Trends in Engineering Research, Volume 8. Issue No.8, Page 4607-4612, August 2020. 